Atmos. Chem. Phys., 17, 13559-13572, 2017

https://doi.org/10.5194/acp-17-13559-2017

(c) Author(s) 2017. This work is distributed under

the Creative Commons Attribution 3.0 License.

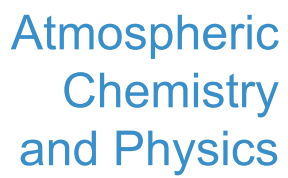

(c) (P)

\title{
Aerosol trends as a potential driver of regional climate in the central United States: evidence from observations
}

\author{
Daniel H. Cusworth ${ }^{1}$, Loretta J. Mickley ${ }^{2}$, Eric M. Leibensperger ${ }^{3}$, and Michael J. Iacono ${ }^{4}$ \\ ${ }^{1}$ Department of Earth and Planetary Sciences, Harvard University, Cambridge, 02138, USA \\ ${ }^{2}$ School of Engineering and Applied Sciences, Harvard University, Cambridge, 02138, USA \\ ${ }^{3}$ Center for Earth and Environmental Science, State University of New York at Plattsburgh, Plattsburgh, 12901, USA \\ ${ }^{4}$ Atmospheric and Environmental Research, Lexington, 02421, USA
}

Correspondence to: Daniel H. Cusworth (dcusworth@fas.harvard.edu)

Received: 7 March 2017 - Discussion started: 29 March 2017

Revised: 6 October 2017 - Accepted: 10 October 2017 - Published: 15 November 2017

\begin{abstract}
In situ surface observations show that downward surface solar radiation (SWdn) over the central and southeastern United States (US) has increased by 0.58 $1.0 \mathrm{Wm}^{-2} \mathrm{a}^{-1}$ over the $2000-2014$ time frame, simultaneously with reductions in US aerosol optical depth (AOD) of 3.3-5.0 $\times 10^{-3} \mathrm{a}^{-1}$. Establishing a link between these two trends, however, is challenging due to complex interactions between aerosols, clouds, and radiation. Here we investigate the clear-sky aerosol-radiation effects of decreasing US aerosols on SWdn and other surface variables by applying a one-dimensional radiative transfer to 2000-2014 measurements of AOD at two Surface Radiation Budget Network (SURFRAD) sites in the central and southeastern United States. Observations characterized as "clear-sky" may in fact include the effects of thin cirrus clouds, and we consider these effects by imposing satellite data from the Clouds and Earth's Radiant Energy System (CERES) into the radiative transfer model. The model predicts that 2000-2014 trends in aerosols may have driven clear-sky SWdn trends of $+1.35 \mathrm{Wm}^{-2} \mathrm{a}^{-1}$ at Goodwin Creek, MS, and $+0.93 \mathrm{Wm}^{-2} \mathrm{a}^{-1}$ at Bondville, IL. While these results are consistent in sign with observed trends, a cross-validated multivariate regression analysis shows that AOD reproduces $20-26 \%$ of the seasonal (June-September, JJAS) variability in clear-sky direct and diffuse SWdn at Bondville, IL, but none of the JJAS variability at Goodwin Creek, MS. Using in situ soil and surface flux measurements from the Ameriflux network and Illinois Climate Network (ICN) together with assimilated meteorology from the North American Land Data Assimilation System (NLDAS), we find that sunnier
\end{abstract}

summers tend to coincide with increased surface air temperature and soil moisture deficits in the central US. The 1990 2015 trends in the NLDAS SWdn over the central US are also of a similar magnitude to our modeled 2000-2014 clear-sky trends. Taken together, these results suggest that climate and regional hydrology in the central US are sensitive to the recent reductions in aerosol concentrations. Our work has implications for severely polluted regions outside the US, where improvements in air quality due to reductions in the aerosol burden could inadvertently pose an enhanced climate risk.

\section{Introduction}

From 1930 to 2004, the eastern and central US experienced significant cooling of as much as $-0.12 \mathrm{~K} \mathrm{a}^{-1}$ (Kumar et al., 2013). This phenomenon is known as the "warming hole," as the temperature trend differs in sign from expected greenhouse gas warming (Pan et al., 2004). More recent observations from this region show average annual temperatures increased by $0.6-0.8 \mathrm{~K}$ between 1901-1960 and 1991-2012, signaling a reversal of the warming hole trend (Melillo et al., 2014). The causes of the warming hole and its subsequent reversal are uncertain. Previous studies have linked the US warming hole to changing patterns in sea surface temperatures (SSTs) such as the Atlantic Multidecadal Oscillation (AMO; Kumar et al., 2013; Zhang et al., 2013) or to trends in anthropogenic aerosols, which may influence meteorology by interacting with solar radiation or clouds (Leibensperger et al., 2012b; Booth et al., 2012; Yu et al., 2014). Banerjee 
et al. (2017) concluded that while aerosols may have contributed to the warming hole, much of the observed cooling arose from unforced internal variability. Most of these studies relied on global or regional climate models, which are inherently uncertain. In this study, we use recent observations and simple models to better constrain the influence of aerosol-radiation interactions on US regional meteorology. In response to tightening air quality regulations, emissions of aerosol sources are expected to decline worldwide over the 21st century (Westervelt et al., 2015), and so our results could have significance for regional climate elsewhere.

Some previous model studies have linked the emergence of a warming hole with changes in SST patterns or largescale circulation. Pan et al. (2004) found that enhanced greenhouse gases produced a circulation response that increased the frequency of the southerly low-level jet over the southern Great Plains in late summer, which in turn replenished soil moisture and suppressed temperature extremes. They concluded this mechanism could induce a warming hole. Using a climate model forced with observed SSTs, Meehl et al. (2012) linked the warming hole cooling trend to the Interdecadal Pacific Oscillation (IPO). Kumar et al. (2013) found that among 22 climate models, those that had the best representation of the AMO also best reproduced the warming hole, although even these models show large discrepancies with the observed trend.

Alternative explanations for the warming hole involve the influence of aerosol trends on regional meteorology, which may include the impact of changing aerosols on SSTs. Over much of the United States, anthropogenic aerosols are dominated by light-colored, highly reflective species such as sulfate. Such aerosols have adverse health effects, and since the 1970s the US EPA has worked to reduce their sources. Between 1990-2010, the Clean Air Act of 1970 and its amendments cut $\mathrm{SO}_{2}$ emissions by $75 \%$ (USEPA, 2012), and this reduction may have affected regional climate. Focusing on June-July-August (JJA) during 2000-2011 across the United States, Yu et al. (2014) found positive correlations between monthly mean satellite observations of aerosol optical depth (AOD) and cloud optical depth (COD, $r=0.76$ ) and between AOD and shortwave cloud forcing (SWCF, $r=0.84$ ), as well as negative correlations between SWCF and maximum surface air temperatures $(r=-0.67)$. They thus attribute the 20th century warming hole to aerosol-cloud interactions that lead to surface cooling. To quantify aerosolradiation interactions, Gan et al. (2014) analyzed a sparse network of surface observations from the Surface Radiation Budget Network (SURFRAD) during 1995-2010, and found increasing trends in annual mean downward surface solar radiation (SWdn) accompanying decreases in AOD, especially among eastern US sites. However, that study also detected an increase in clear-sky diffuse radiation, which is perplexing, given that declining aerosol would be expected to decrease such radiation. In contrast, Eshel (2016) diagnosed 19982014 surface observations at a site in upstate New York, and inferred that improved air quality has led to a strong increase in JJA SWdn there. The Eshel (2016) result is similar to European studies that have tied aerosol reductions to enhanced SWdn (Philipona et al., 2009; Ruckstuhl et al., 2008). Tosca et al. (2017) compared the observed $+0.54 \pm 0.52 \mathrm{~K}$ decade $^{-1}$ summertime temperature trend in the southeast US to the $-0.05 \mathrm{decade}^{-1}$ satellite retrieved AOD trend. The authors conclude that aerosols reductions enhanced surface temperature through aerosol-radiation interactions, but their study did not consider the covariability between observed clear-sky SWdn and AOD measurements, which we argue should exist for aerosol-radiation interactions.

In a modeling framework, Mickley et al. (2012) found that simple removal of US aerosols exerted a top-of-atmosphere (TOA) radiative forcing of as much as $+4-5 \mathrm{Wm}^{-2}$ over the central and eastern US. This forcing produced a positive feedback in which increases in SWdn enhanced surface fluxes of sensible heat in late summer, drying out soils and reducing cloud cover, which further enhanced SWdn. To understand the climate response of a more realistic representation of US aerosols, Leibensperger et al. (2012a) forced a global climate model using simulated historical aerosols, and found that high aerosol loading during 1970-1990s increased cloud cover and soil moisture by as much as $5 \%$ in the central and eastern US. The study also found that aerosol outflow to the Atlantic Ocean in this time frame may have cooled SSTs and increased mean JJA $850 \mathrm{hPa}$ geopotential heights in the region of the Bermuda High (BH), a semipermanent high-pressure system. Booth et al. (2012) found that stronger aerosol influence on surface forcing in a climate model could better reproduce Atlantic SSTs. Zhang et al. (2013) contested this result, pointing to mismatches between the Booth et al. (2012) model results and observations of North Atlantic upper ocean heat content and salinity. They proposed instead that variations in the Atlantic Multidecadal Overturning Circulation have driven recent changes in Atlantic SSTs. Mascioli et al. (2016) found competing effects on US temperature extremes by changing aerosols and greenhouse gases over the 20th century, as expected, but temperature in the southeast responded only weakly to aerosols in their simulation. Finally, using 50-member ensembles, Banerjee et al. (2017) simulated aerosol-radiation interactions and the cloud albedo effect on US climate, but not the cloud lifetime effect. They found that aerosol forcing could not entirely explain the 1951-1975 decreasing JJA trend in southeastern US temperatures.

Nearly all these studies on the origin of the US warming hole relied on climate or chemistry-climate models with their many uncertainties. For example, the response of soil moisture or low cloud cover to changing SWdn in such models may not be well captured (Soden and Held, 2006), and with few observations, aerosol concentrations in the early warming hole years are not well constrained. Aerosol composition is also not well known in the 1950s and 1960s, with black carbon emissions likely uncertain by at least a factor of 2 
(Bond et al., 2007). The meteorological response to black carbon could be very different to that of sulfate (Koch and Del Genio, 2010; Bond et al., 2013), the most abundant anthropogenic aerosol in more recent decades.

In this paper, we turn to observational datasets to try to reconcile the apparently conflicting hypotheses of previous studies (e.g., Leibensperger et al., 2012b; Kumar et al., 2013; Gan et al., 2014; Yu et al., 2014). We extend previous analyses of SURFRAD trends (Long et al., 2009; Augustine and Dutton, 2013; Gan et al., 2014) by using more recent observations and by focusing on two central and eastern US sites, where emission controls have had the largest influence on AOD. To gain knowledge of the potential influence of changing AOD on regional meteorology, we apply the observed AOD and cirrus cloud variables to a radiative transfer model and a simple statistical model. We further study regional meteorology during summers with enhanced SWdn to better understand how potential trends in SWdn could influence climate and soil hydrology, especially if the warming hole reversal continues, as suggested by some modeling studies (Leibensperger et al., 2012b). Our work has special relevance for developing countries that currently experience heavy aerosol loading but are planning emission reduction strategies (e.g., Lu et al., 2011).

\section{Data and methods}

We obtain surface SWdn observations from the SURFRAD Network, which consists of seven sites across the US (Augustine et al., 2000). Although sparse, the network provides some of the longest in situ solar radiance measurements in the US, broken into diffuse and direct components. In this study we focus on 2000-2014 data from sites in Bondville, Illinois, and Goodwin Creek, Mississippi, as these sites are located in the central and eastern US and have experienced AOD reductions in the recent past (Gan et al., 2014). We exclude the SURFRAD Penn State site from this study, as the record is incomplete for much of 2009-2014. SURFRAD solar diffuse radiation is measured through a shaded Eppley Black and White Pyranometer, and direct solar radiation is measured with an Eppley Normal Incidence Pyrheliometer (NIP). Diffuse and direct measurements are summed to produce all-sky shortwave radiation fluxes. All broadband radiation measurements have a $3 \mathrm{~min}$ temporal resolution, taken as an average of $1 \mathrm{~s}$ samples. There are uncertainties of 3 and $6 \%$ ( 4 and $20 \mathrm{Wm}^{-2}$ ) associated with the direct and diffuse measurements, respectively (Stoffel, 2005), where uncertainty is derived from the $95 \%$ confidence interval. SURFRAD stations also measure AOD in five spectral channels using a multifilter shadowband radiometer. The AOD data are also available as 3 min averages, but only under cloud-free conditions. Both SURFRAD sites are located away from urban sources, so we expect them to be representative of the larger region. To verify consistency of
SURFRAD trends against trends across the broader region, we compare the SURFRAD SWdn radiance data with pyranometer measurements from the US Climate Reference Network (USCRN; Diamond et al., 2013), but consider only those USCRN sites that have $10+$ years of data, starting as early as 2003. We also compare SURFRAD SWdn to in situ pyranometer measurements from the Cary Institute of Ecosystem Studies (CIES; http://www.caryinstitute.org), located near Millbrook, New York, from 1990 to 2015.

SURFRAD also provides estimates of total clear-sky radiance using the all-sky observations, following the methods in Long and Ackerman (2000). Briefly, a power law model ( $Y=A \times \cos (\theta) b)$ is fit, where the initial guess for $Y$ is allsky $\mathrm{SWdn}, \theta$ is the solar zenith angle, and $\mathrm{A}$ and $\mathrm{b}$ are the fitted coefficients. After eliminating cloudy measurements using various selection criteria, the power law model is refit following an iterative process until its coefficients converge, giving an estimate of clear-sky fluxes. A weakness of this fitting algorithm is that it may not remove the influence of thin cirrus clouds on the clear-sky flux (Long et al., 2009), and trends in cirrus cloud cover may potentially influence estimates of trends in clear-sky SWdn.

We use the column version of the rapid radiative transfer model for general circulation models (RRTMG_SW) to relate SURFRAD radiances to changes in AOD at the two sites (Iacono et al., 2008). RRTMG_SW relies on a correlated- $k$ approach to approximate radiative fluxes and heating rates (Clough et al., 2005); multiple scattering is calculated through a two-stream approximation. We apply monthly mean profiles of atmospheric temperature, pressure, and ozone and water mixing ratios from the MERRA2 reanalysis (Rienecker et al., 2011) while keeping all other chemical profiles (e.g., $\mathrm{CO}_{2}$ and $\mathrm{N}_{2} \mathrm{O}$ ) fixed to climatological means. The MERRA-2 ozone product is derived from a simple production and loss chemical scheme (Suarez et al., 2008), assimilated with measurements from the Ozone Monitoring Instrument and the Microwave Limb Sounder. MERRA-2 ozone fields below $260 \mathrm{hPa}$ are not as reliable. We also apply MERRA-2 surface emissivities to the RRTMG_SW bands in the infrared part of the spectrum $\left(820-4000 \mathrm{~cm}^{-1}\right)$, and one minus the observed SURFRAD SW reflectance in the RRTMG_SW bands in the shortwave region (4000-50000 $\mathrm{cm}^{-1}$ ).

We drive the model with observed monthly mean AOD from SURFRAD. For single scattering albedo and asymmetry parameters of the aerosol, we rely on measurements from two long-term AERONET sites located close to the SURFRAD sites: Bondville, IL, and Huntsville, AL (Dubovik and King, 2000). Gan et al. (2014) found close agreement between AOD measurements at the Bondville SURFRAD site and nearby AERONET sites, so we assume that AERONET aerosol properties represent those at SURFRAD. For information on thin cirrus clouds, we rely on cloud fraction, cloud water path, and ice and liquid radius data retrieved from the CERES instrument onboard the Terra 
and Aqua satellites (Minnis et al., 2011). CERES thin cirrus cloud optical depths have been shown to those retrieved by the Cloud-Aerosol Lidar and Infrared Pathfinder Satellite (launched in 2006) over land $(r=0.65)$. More detailed information about the cirrus retrieval uncertainty is currently being explored (Minnis, P., personal communication, 2017). Since we are interested in total column extinction and surface radiation values, we assume all aerosols are concentrated in the surface layer and fix cirrus fractional cloudiness at $300 \mathrm{hPa}$. In a sensitivity simulation, we find that whether we fix the aerosols at the surface layer or distribute the aerosol through the lower troposphere has little effect on modeled surface SWdn. Since the CERES Level 3 retrieval is available only since 2000 , we perform all monthly radiative transfer simulations over the 2000-2014 period. Our model setup is similar to the approach of Ruiz-Arias et al. (2013), who performed Weather Research and Forecasting (WRF) model simulations using RRTMG_SW driven by AERONET AOD and aerosol parameters during 1-3 October 2011. The authors found close agreement between 10 min modeled and observed total, direct, and diffuse SWdn at SURFRAD and Atmospheric Radiation Measurement (ARM) sites, though they did not perform simulations for Goodwin Creek. We perform simulations with monthly mean data to avoid gaps in the AOD and CERES record. Missing daily observations at Goodwin Creek and Bondville range from 43 to $49 \%$.

To assess the regional climate impacts of variations in SWdn at Bondville, we use tower data from the nearby Ameriflux site, also in Bondville, and Illinois Climate Network (ICN) sites (WARM, 2014). The Ameriflux site provides 9 years (1998-2007) of continuous observations of summertime radiation, temperature, heat flux, and soil moisture. The tower is located within an active corn and/or soybean agriculture field, but experiences little irrigation (Meyers, T., personal communication, 2016), which could influence the microclimate. The Bondville ICN tower sits in a non-irrigated grass field. Between 1983-2002, semimonthly soil moisture measurements were made at the tower, using a neutron probe instrument. Since 2003, the station has taken hourly soil moisture measurements using a hydraprobe sensor. The ICN site also provides shortwave global radiation, temperature, and soil temperature data from 1990 to the present.

We compare Ameriflux and ICN tower data with the estimates from the NASA Land Data Assimilation System (NLDAS) over North America (Mitchell et al., 2004). The goal of the NLDAS project is to construct high-quality, consistent datasets for use in land surface models (LSMs). NLDAS utilizes a combination of gauge-based precipitation and meteorological data from the NCEP North American Regional Reanalysis (NARR) to drive an ensemble of LSMs, yielding estimates of soil moisture and surface energy fluxes. Version 2 of NLDAS also uses bias-corrected SWdn data from the University of Maryland Surface Radiation Budget dataset, which is based on GOES-8 satellite data (Pinker et al., 2003). Here we analyze the output from three LSMs in the NLDAS project: Mosaic, Variable Infiltration Capacity (VIC), and Noah (Xia et al., 2012; Koster and Suarez, 1994; Wood et al., 1997). Each LSM has a different treatment of land-atmosphere coupling, but all require that incoming solar radiation balance the sum of outgoing thermal radiation, latent and sensible heat losses, and diffusion of energy into the soil (Overgaard and Rosbjerg, 2011). Spatial resolution of these models is $1 / 8^{\circ} \times 1 / 8^{\circ}$.

We calculate annual trends in observations using monthly mean anomalies. For the SURFRAD dataset, we first find the mean diurnal profile for each month during 2000-2014. We then calculate monthly mean SWdn by averaging these diurnal profiles over daylight hours. We compute the monthly climatology over the 2000-2014 period and subtract that from each year's monthly means to arrive at monthly SWdn anomalies. Trends for other data measured with hourly or daily frequency are computed using the same method. Radiative transfer simulations in RRTMG_SW are performed with monthly average AOD and other environmental variables. As with the observations, we find monthly anomalies in RRTMG_SW by first calculating the 2000-2014 monthly climatology for each simulation and subtracting that from the corresponding time series of monthly means. We use leastsquares regression to estimate the slopes of the time series of both observed and modeled monthly anomalies. To test for statistical significance, we follow the method described by Weatherhead et al. (2008), a method also utilized by Gan et al. (2014). This method determines the significance of a least-squares trend based on variance of the noise (i.e., the residual from the straight-line fit), the autocorrelation of the noise, and the number of data points used to determine the trend. In this study, we set $p<0.05$ as the threshold for statistical significance.

\section{Long-term trends in surface SWdn}

Observed $500 \mathrm{~nm}$ AOD decreases significantly at both Bondville $(-0.047)$ and Goodwin Creek $(-0.052)$ during the 2000-2014 time frame (Fig. 1), providing evidence of the success of strengthening US air quality regulations. In Fig. 2 we show the corresponding trends in observed SWdn for allsky and clear-sky conditions at the two sites. Both stations show significant increases in total (diffuse + direct) all-sky as well as clear-sky SWdn, as would be expected from the changes in AOD. However, diffuse SWdn is the dominant contributor to these clear-sky trends in both cases, a finding that is discussed further in this section and Sect. 4.

Figure 2 also shows the modeled trends in SWdn. At Bondville, the aerosol-only simulated trend in clear-sky SWdn agrees in magnitude and sign $\left(+0.93 \pm 0.22 \mathrm{Wm}^{-2} \mathrm{a}^{-1}\right) \quad$ with that observed $\left(+0.85 \pm 0.13 \mathrm{Wm}^{-2} \mathrm{a}^{-1}\right)$. Breaking down the total SWdn into its direct and diffuse components, the aerosol- 

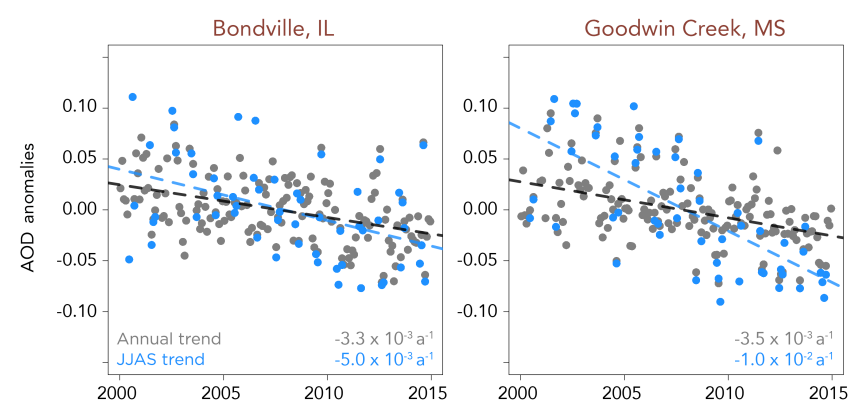

Figure 1. Trends in monthly anomalies of $500 \mathrm{~nm}$ aerosol optical depth (AOD) at Bondville, IL, and Goodwin Creek, MS, during 2000-2014. All trend lines pass the significance threshold $(p<0.05)$.

only simulation shows a result consistent with aerosol reductions, specifically large increases in direct SWdn accompanied by a decrease in diffuse SWdn. However, this result differs from clear-sky observations, which show both direct and diffuse SWdn increasing $(+0.41 \pm 0.16$ and $\left.+0.44 \pm 0.11 \mathrm{Wm}^{-2} \mathrm{a}^{-1}\right)$.

As noted above, thin cirrus clouds may influence SWdn even under apparently clear-sky conditions. Figure 3 shows spatial trends in cirrus ice cloud fraction over 2000-2014 from CERES. Cirrus cloud fraction increases as much as $+0.5 \% \mathrm{a}^{-1}$ over parts of the eastern US, with a $+0.21 \% \mathrm{a}^{-1}$ increase over Bondville. Trends in two other cirrus cloud properties - cloud water path and cloud particle radius - are not as spatially coherent as those of cirrus cloud fraction, and we do not discuss these further. Incorporating the cirrus cloud fraction and the other two cloud parameters into the aerosolcirrus simulation still yields an increasing trend in total clearsky SWdn as shown in Fig. $2\left(+0.40 \pm 0.29 \mathrm{Wm}^{-2} \mathrm{a}^{-1}\right)$, but with a magnitude only about half that observed. Diffuse SWdn in this simulation is roughly a third of the observed clear-sky trend, and this match comes at the expense of direct SWdn, which now shows a decreasing trend, in contradiction to the observations. Neither the direct nor diffuse SWdn trends in the aerosol-cirrus simulation are statistically significant.

At Goodwin Creek, the modeled aerosol-only simulation trend in clear-sky SWdn is $+1.35 \pm 0.25 \mathrm{Wm}^{-2} \mathrm{a}^{-1}$, more than double the observed clear-sky trend $\left(+0.52 \pm 0.14 \mathrm{Wm}^{-2} \mathrm{a}^{-1}\right)$. As at Bondville, the diffuse component of the observed clear-sky SWdn at Goodwin Creek also exhibits an increasing trend $\left(+0.34 \pm 0.11 \mathrm{Wm}^{-2} \mathrm{a}^{-1}\right)$, even though cirrus cloud fraction shows no significant trend there (Fig. 3). In fact, the diffuse SWdn trend in the aerosol-cirrus simulation at Goodwin Creek is still negative, though more positive than the aerosol-only simulation. This result contrasts with that in Bondville, where consideration of the large cirrus trend changed the sign and significance of direct and diffuse SWdn trends.
Reconciling the observed trends in diffuse, direct, and total SWdn at the two sites is challenging. In their analysis of SURFRAD data, Gan et al. (2014) also found increasing trends in clear-sky diffuse SWdn averaged over seven sites across the US from 1995 to 2010. That study hypothesized that trends in this variable could be traced to increasing air traffic and enhanced thin cirrus cloud formation. The effect of aircraft contrails on total cirrus cloud fraction is uncertain. Analyzing trends in upper-atmosphere humidity and cirrus cloud cover, Minnis et al. (2004) determined that the observed 1971-1995 $+1.0 \%$ per decade $\left(+0.1 \% \mathrm{a}^{-1}\right)$ increase in cirrus cloud fraction over the US was indeed caused by increased air traffic. The magnitude of this trend is similar to what we observe in Fig. 3. Consistent with Minnis et al. (2004), Travis et al. (2004) found the diurnal temperature range (DTR) over the entire US increased by $1.0 \mathrm{~K}$ compared to the 1971-2000 climatological mean after the 3-day suspension of nearly all air traffic following the events on 11 September 2001, with especially large increases (1-2 standard deviations above the climatological mean) in regions such as Illinois that favor the formation of aircraft contrails at high altitudes. The conclusions of the Minnis et al. (2004) finding, although controversial (Hong et al., 2008), suggest a strong influence of contrails on the surface energy budget. At the two SURFRAD sites, we do not find evidence in the diffuse SWdn record of a response to the abrupt halt to air traffic in September 2001 (Fig. S1 in the Supplement). At Bondville, a slight enhancement in diffuse radiation occurred 1 day after 11 September which then decayed to the 1995-2000 average after 2 weeks. Enhancements of similar magnitude occur previous to 11 September so excursions from the mean may be typical for diffuse SWdn at Bondville. Diffuse SWdn at Goodwin Creek site exhibits a jump on 11 September above the 1995-2000 climatology, but mostly stays within 1 standard deviation of the 1995-2000 average afterward. These jumps in diffuse SWdn around 11 September would seem to contradict an influence of contrails on surface SWdn observations. However, it is also possible that the sites are simply not representative of the larger domain during this short time frame. However, since we do not see strong evidence of aircraft influencing the diffuse clear-sky SWdn at Bondville during 11-13 September, we are cautious in ascribing the increasing diffuse clear-sky SWdn trends simulated at Bondville (Fig. 2) to aircraft contrails. The increasing trend in CERES cirrus cloud fraction (Fig. 3) may be due to other factors that are outside the scope of this paper.

\section{Short-term variability in SWdn}

The 2000-2014 trends in total observed and modeled clearsky SWdn are positive at both Bondville and Goodwin Creek, implying a link between aerosols and SWdn. However, surface clear-sky SWdn would be expected to respond rapidly to changes in overhead aerosol, and here we check whether 

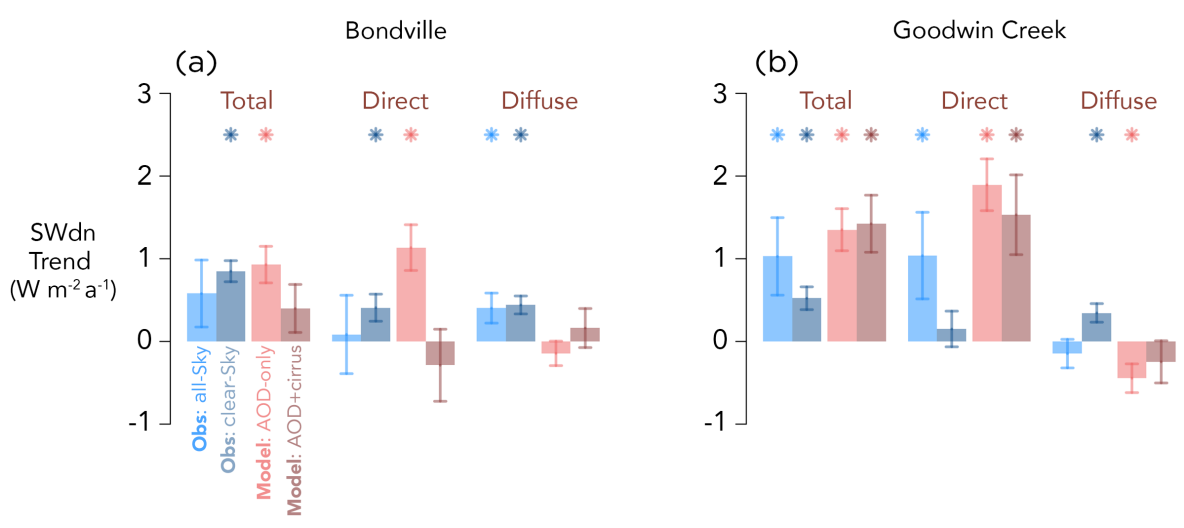

Figure 2. Annual trends in downward surface solar radiation (SWdn) during 2000-2014 at Bondville, IL (a), and Goodwin Creek, MS (b). Trends are determined from daytime data (10:00-23:00 UTC). Trends in observed all-sky SWdn from the SURFRAD network are shown in light blue; observed trends in clear-sky SWdn are in dark blue. Modeled trends in clear-sky SWdn are shown for an aerosol-only simulation (light red) and for a simulation with both aerosols and cirrus clouds included (dark red). Error bars are the standard error of the slope estimated from a linear regression fit. Asterisks above the bars indicate statistical significance $(p<0.05)$.

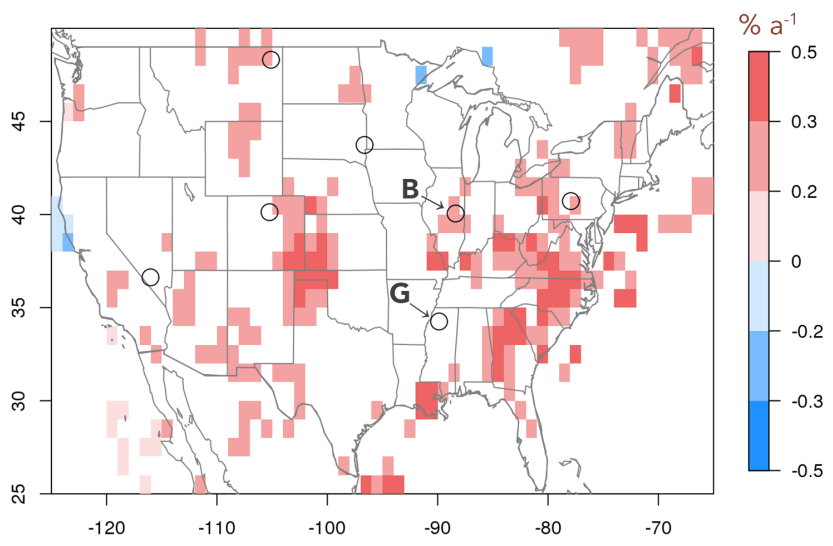

Figure 3. Annual trends in cirrus ice cloud fraction as retrieved from Clouds and Earth's Radiant Energy System (CERES) for 2000-2014. Black circles represent the locations of the SURFRAD stations ( $\mathrm{B}=$ Bondville, IL; $\mathrm{G}=$ Goodwin Creek, MS). White indicates regions where trends are not statistically significant $(p>0.05)$.

changes in aerosols and/or cirrus clouds can explain the monthly variability of clear-sky SWdn observations. Figure 4 shows the time series of observed and standardized monthly mean SWdn anomalies at Bondville and Goodwin Creek, together with SWdn results from the aerosol-only and aerosol-cirrus radiative transfer simulations. The standardized time series is constructed by differencing each month's value with the long-term monthly mean and then dividing by the monthly standard deviation. The Bondville aerosol-only simulations show greater correlation with observations (e.g., $r=0.49$ for total SWdn) than that for the aerosol-cirrus simulations $(r=0.29)$. At Goodwin Creek, results from neither monthly simulation are significantly correlated with monthly observations.
For AOD to be a controlling factor of clear-sky SWdn, we would expect covariability between variables. To check whether this connection is robust, we develop a statistical model to predict surface monthly mean clear-sky SWdn anomalies based on AOD and cirrus cloud properties using multivariable linear regression (MLR) with no lag. We perform MLR for June-July-August-September (JJAS). Aerosol load is generally highest in the US during these months (Malm et al., 2004), the incoming solar flux is large, and feedbacks can extend the aerosol influence into late summer (Mickley et al., 2012). We find the optimal coefficients of the MLR by individually fitting independent models across all combinations of predictor variables. For predictor variables, we use AOD and the same cirrus cloud parameters used to drive RRTMG_SW aerosol-cirrus simulations cirrus cloud liquid water path (LWP), cirrus cloud ice water path (IWP), cirrus cloud liquid radius $\left(R_{\mathrm{L}}\right)$, cirrus cloud ice radius $\left(R_{\mathrm{I}}\right)$, and cirrus cloud fraction $\left(C_{\mathrm{f}}\right)$. We also include monthly average column ozone (pressure weighted) as a predictor. We optimize coefficients for each individual MLR fit using leave-one-out cross-validation. For each MLR fit, we calculate the Bayesian information criterion (BIC), which scores the MLR based on its goodness of fit and penalizes based on the number of parameters included in the regression (Posada and Buckley, 2004). Thus, we seek solutions that explain clear-sky SWdn using the fewest number of terms, so as to avoid over-fitting. Both clear-sky SWdn and the predictors are detrended, deseasonalized, and standardized before the MLR is fit.

Table 1 summarizes the coefficients of the optimal MLR fits to clear-sky SWdn. At Bondville, we find the optimal clear-sky total SWdn MLR model is driven by AOD and overhead ozone, explaining $15 \%$ of the variance. Direct SWdn is best explained $(20 \%)$ by AOD alone. The MLR model with AOD and cirrus LWP best fits the observed vari- 

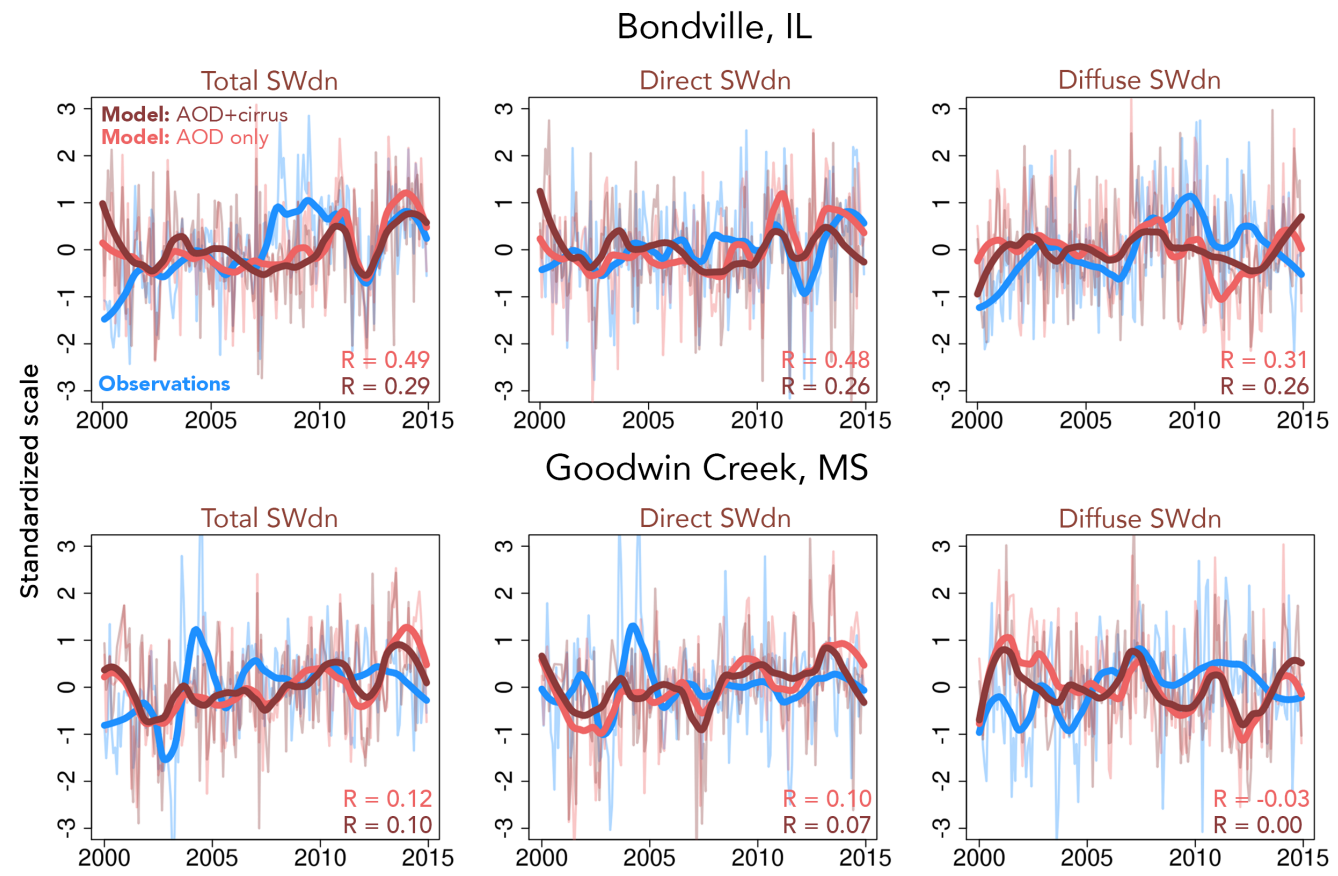

Figure 4. Time series of monthly mean anomalies (standardized by mean and standard deviation) in surface solar radiation (shortwave down or SWdn) at Bondville, IL, and Goodwin Creek, MS, from 2000 to 2014. Blue curves denote observations, light red shows model results with observed aerosol optical depths (AOD) taken into account, and dark red shows results when both AOD and observed cirrus cloud fraction are included. Thick lines represent a 3-year locally weighted scatter-plot smoothing (lowess). The correlations $R$ between the nonsmoothed model simulations and observations are shown inset. All the correlations at Bondville are significant $(p<0.05)$, and no correlations at Goodwin Creek are significant.

ability in clear-sky diffuse SWdn, explaining $26 \%$ of the variance. The magnitude of the fitted AOD coefficients are of similar magnitude and opposite sign for direct and diffuse SWdn, consistent with the expectation for aerosol-radiation interactions. The coefficients of determination $\left(R^{2}\right)$ in Table 1 are similar in magnitude to the correlations between observed SWdn fluxes and those calculated by the radiative transfer model (Fig. 4), showing a consistency between the two methods to interpret the influence of AOD on SWdn.

At Goodwin Creek, neither observed AOD nor any property of cirrus clouds can explain the variability in direct or diffuse SWdn, casting doubt on these variables as influences on SWdn at this site. That two separate sites with similar 2000-2014 AOD reductions could have different MLR results underscores the possible multiplicity of drivers of SWdn and the uncertainty in resolving local radiation budgets. RRTMG_SW simulations driven by AOD have been shown to capture SWdn fluxes at SURFRAD sites well (Ruiz-Arias et al., 2013). However, Ruiz-Arias et al. (2016) found a $4 \%$ reduction in monthly mean AOD compared to daily AOD in fine aerosol regimes. (Ruiz-Arias et al. segregate aerosol regimes using the Angstrom exponent, which is a direct function of the average size of the aerosol mixture.) Among the Bondville and Goodwin Creek AOD time series and the CERES retrievals, nearly half the days are missing
Table 1. Fitted regression coefficients to downward surface shortwave radiation (SWdn) at Bondville, IL, from 2000 to 2014. Fits represent the optimal multivariate regression model chosen using the Bayesian Information Criterion (BIC) and fit to columnaveraged ozone, aerosol optical depth (AOD), cirrus cloud liquid water path (LWP), cirrus cloud ice water path (IWP), cirrus cloud liquid radius $\left(R_{\mathrm{L}}\right)$, cirrus cloud ice radius $\left(R_{\mathrm{I}}\right)$, and cirrus cloud fraction $\left(C_{\mathrm{f}}\right)$.

\begin{tabular}{llc}
\hline SWdn & Regression Fits* & $R^{2}$ \\
\hline Total & -0.27 AOD + 0.30 Ozone & $15 \%$ \\
Direct & -0.45 AOD & $20 \%$ \\
Diffuse & 0.44 AOD + 0.29 LWP & $26 \%$ \\
\hline
\end{tabular}

* Predictor variables were detrended, deseasonalized, and normalized by their mean and standard deviation before being fitted to SWdn anomalies.

coincident observations, hence the need to bin the daily data into monthly observations.

\section{Meteorological impacts from enhanced SWdn in late summer}

Previous work has suggested that the land-atmosphere coupled response to increased SWdn involves a cascade of mete- 
orological phenomena (Shindell et al., 2003; Budyko, 1969). $\mathrm{Gu}$ et al. (2006) saw evidence of coupling between net radiation, heat fluxes, and soil moisture using Ameriflux observations during the 2005 growing season in Missouri. The model study of Mickley et al. (2012) found that US aerosol reductions lead to enhanced latent heat fluxes in early summer, which transition to enhanced sensible heat fluxes by late summer-early fall. We probe the observational record for evidence of these feedbacks by first analyzing 1998-2007 tower data from the Ameriflux site at Bondville. We classify the data for each year into either a sunny or cloudy regime depending on whether the JJAS mean SWdn for that year is above or below the climatological JJAS median. We chose JJAS as the time frame of reference due to the large summer to early fall SWdn response from reduced aerosols seen in Mickley et al. (2012). We then compare the responses in monthly mean surface fluxes for these two regimes (Fig. 5). We do not consider aerosols directly here, as the short time series of the Ameriflux data limits the ability to assess longterm trends, but we can use our results to understand the regional sensitivity of the land-atmosphere system to SWdn changes driven by AOD trends. We also do not consider microclimate feedbacks from irrigation at the Ameriflux station. Although irrigation has been shown in other studies to suppress extreme temperatures in the Midwest (Mueller et al., 2016), we find that the monthly-average temperatures recorded at the Ameriflux Bondville site nearly match the temperature readings at the nearest airport in Champaign, IL (not shown). Also, since the Ameriflux temperatures and SWdn data correspond closely to these value in the $1 / 8^{\circ}$ NLDAS dataset (Fig. S2), we assume that the effect of microscale irrigation is small.

Figure 5 shows that the difference in all-sky daytime SWdn between these two regimes during JJAS is $+28.1 \mathrm{Wm}^{-2}$. Enhanced SWdn during sunny years leads to increased latent heat fluxes in May-June $\left(+5.3 \mathrm{Wm}^{-2}\right)$, which transition to increased sensible heat fluxes in AugustOctober $\left(+9.5 \mathrm{Wm}^{-2}\right)$. Volumetric soil water content follows the latent and sensible heat fluxes, with greater soil moisture in June $(+2.7 \%)$ and drier conditions in August $(-3.5 \%)$. Because of the increased sensible heating in the sunny regime, we would expect a corresponding change in temperature. However, the difference in JJAS maximum temperature at this site is slightly negative $(-0.86 \mathrm{~K})$, with cooler temperatures during sunny years. This negative change in temperature is corroborated by a negative change in upward surface longwave radiation (LWup) at the nearby SURFRAD site $\left(-5.4 \mathrm{Wm}^{-2}\right)$. Precipitation at Bondville does not differ significantly between sunny and cloudy regimes (not shown). Summer 2004, classified as sunny, was paradoxically the coolest summer in the Ameriflux record, with a mean maximum temperature $1.7 \mathrm{~K}$ cooler than the 1998-2007 average at this site. Indeed much of the central US experienced cool temperatures that summer (w2.weather.gov/dtx/2004annualclimatesummary). The sur-
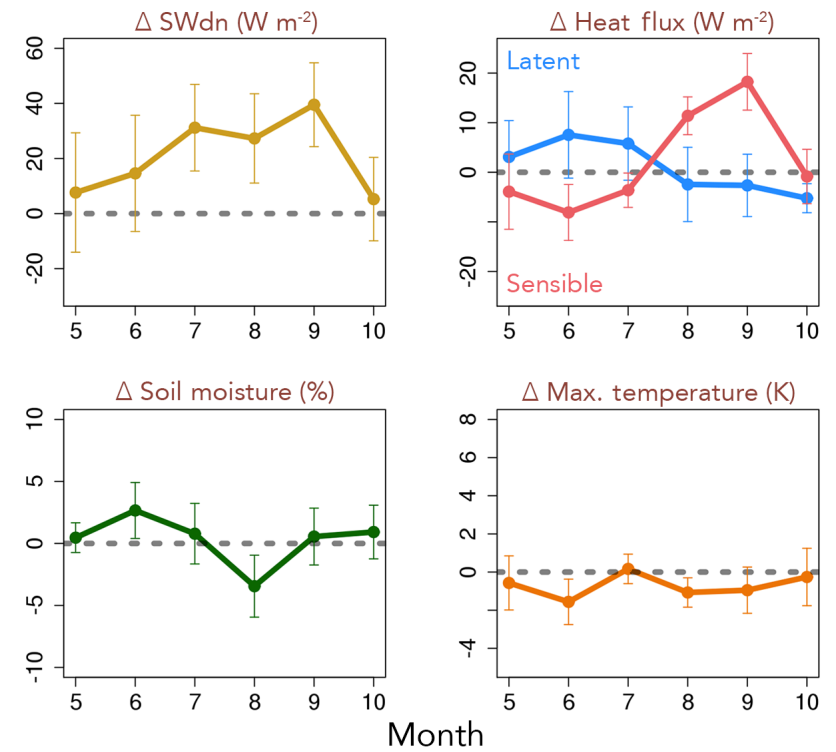

Figure 5. Differences in surface measurements at the Bondville Ameriflux site (1998-2007) between sunny and non-sunny summers, where summer is defined as June-July-August-September and a sunny summer is defined as one with average all-sky downward surface solar radiation (SWdn) greater than the median 19982007 all-sky summer SWdn. Error bars represent the $95 \%$ confidence interval of the difference.

prising result of a cool but sunny summer in 2004 at the Ameriflux site points to the possible problem of relying on its short (10 year) record of observations.

We next examine ICN measurements of SWdn and surface variables, including soil moisture, using the same method of segregating sunny and cloudy summers. Since the method of measuring ICN soil moisture changed in 2003 , we analyze differences in sunny vs. cloudy regimes within each measurement period, with PER1 corresponding to 1990-2002, and PER2 corresponding to 2003-2014. Though no sensible or latent heat measurements are available here, the ICN data include a record of 4 in $(10.2 \mathrm{~cm})$ soil temperatures under sod together with soil moisture and maximum air temperatures (Fig. 6). We see a similar pattern across the two instrument regime periods, specifically that sunny JJAS summers (PER $1=+16.3 \mathrm{Wm}^{-2}$, PER2 $=+8.5 \mathrm{Wm}^{-2}$ ) favor hotter soils $($ PER1 $=+1.2 \mathrm{~K}$, PER2 $=+2.9 \mathrm{~K})$ and reduced soil volumetric water content $($ PER $1=-3.0 \%$, PER $2=-3.4 \%)$. In both instrument periods, the maximum JJAS temperature increases during sunny summers $(\mathrm{PER} 1=+2.0 \mathrm{~K}, \mathrm{PER} 2=+2.5 \mathrm{~K})$, in contrast with the Ameriflux measurements. In the PER2 ICN data, summer 2004 is categorized as cloudy, hence its cooler temperature is expected. The LWup change at the nearby SURFRAD site during PER2 is consistent with the temperature increase $\left(+4.8 \mathrm{Wm}^{-2}\right)$. Precipitation again does not differ significantly between sunny and cloudy regimes for each 

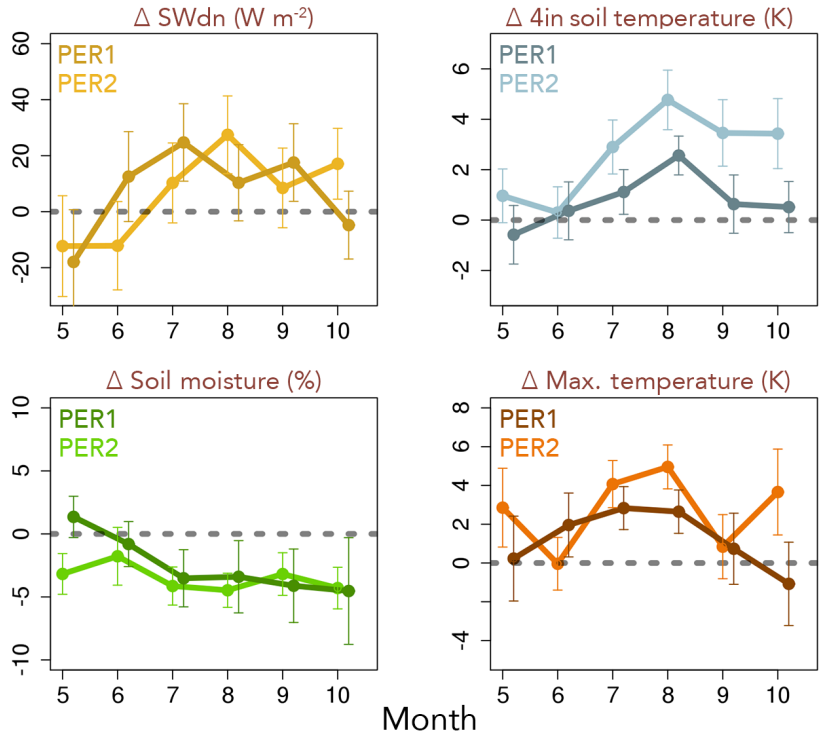

Figure 6. Differences in surface measurements at the Bondville ICN site between sunny and non-sunny summers. The technique for measuring soil moisture changed at this site in 2003, and the panels show differences separately for the periods before and after this change: period 1 (PER1, 1990-2002) and period 2 (PER2, 2003-2014). As in Fig. 5, summer is defined as June-July-AugustSeptember and a sunny summer is defined as one with average allsky downward surface solar radiation (SWdn) greater than the median all-sky summer SWdn of each respective period. Error bars represent the $95 \%$ confidence interval of the difference. For clarity, monthly means for PER1 are slightly offset with respect to the abscissa.

instrument period (not shown). The changes in SWdn for both ICN and Ameriflux stations are strongly positive, with the change during both PER1 and PER2 about half that in the Ameriflux record.

The record of observations at Ameriflux Bondville is relatively short, and the inconsistent soil instrument record at the ICN station complicates long-term analysis. Ameriflux and ICN sites yield consistent SWdn and soil moisture results, but different surface temperature responses, perhaps due to the short-term measurement record. To investigate long-term land-atmosphere changes from 1990 to 2015, we use assimilated meteorology and other variables from the NLDAS dataset. To assure the quality of the NLDAS driving variables, we compare three of these variables - monthly mean SWdn, precipitation, and air temperatures - with observations from Ameriflux stations with at least 5 years of data (11 in total). We also compare NLDAS SWdn with that from SURFRAD. Figure S2 shows statistically significant agreement among these datasets, with $r$ ranging from 0.60 to 0.77 , depending on the variable. We find much weaker, but still statistically significant, agreement between the LSM results and the Ameriflux observations, with $r$ ranging from 0.24 to 0.47 , depending this time on both the variable and model (Fig. S2).
Best matches between models and measurements are obtained for the sensible heat flux. The relatively weak correlations underline the difficulty in resolving land-atmosphere coupling at $1 / 8^{\circ} \times 1 / 8^{\circ}$ resolution.

Using the NLDAS dataset and being mindful of the uncertainties in LSM results, we expand our focus to look at spatial trends in the relevant variables across the contiguous United States for JJAS over the 1990-2015 time period. Figure 7 shows that surface JJAS all-sky SWdn has increased significantly by $+0.78 \mathrm{Wm}^{-2} \mathrm{a}^{-1}$ from 1990 to 2015 across the central US $\left(30-50^{\circ} \mathrm{N}, 105-85^{\circ} \mathrm{W}\right.$, denoted by the green box in Fig. 7). Figure 7 also reveals a close correspondence between the all-sky NLDAS trend and the all-sky trends derived from site measurements in the SURFRAD (1997-2014), USCRN (2003-2014), and CIES (1990-2015) networks, increasing confidence in the NLDAS dataset. Deviations between data products may be explained by the inconsistent time periods of comparison. Accompanying the change in SWdn is an increase in average JJAS air temperatures over much of the central and eastern US $\left(+0.07 \mathrm{~K} \mathrm{a}^{-1}\right)$. Precipitation decreases slightly in the central US $\left(-0.19 \mathrm{~kg} \mathrm{~m}^{-2} \mathrm{a}^{-1}\right)$, mostly in a few isolated regions over the Great Lakes. The total JJAS enhancement in NLDAS all-sky SWdn over the central US over the 1990 2015 time period is $+20 \mathrm{Wm}^{-2}$, similar in magnitude to the increase observed during sunny years at the Ameriflux $\left(+28.1 \mathrm{Wm}^{-2}\right)$ and ICN $\left(\right.$ PER $1=+16.3 \mathrm{Wm}^{-2}$, PER $2=$ $+8.5 \mathrm{Wm}^{-2}$ ) sites. The 2000-2014 clear-sky SWdn enhancements that we simulate with RRTMG_SW at Bondville and Goodwin Creek $\left(+13.9\right.$ and $\left.+6.2 \mathrm{Wm}^{-2}\right)$ are about half the NLDAS enhancements averaged over the central US for the longer time period of 1990-2015.

Figure 7 also shows the soil moisture response to increasing SWdn and warmer temperatures over 1990-2015, as calculated by the three LSMs. We combine LSM results by first determining which of the model trends agree in sign in each grid cell and then taking the mean of just those models that agree. The combined trend reveals decreased soil moisture across the central US between 1990 and $2015\left(-0.85 \mathrm{~kg} \mathrm{~m}^{-2} \mathrm{a}^{-1}\right.$, averaged over the region defined in Fig. 7), accompanied by an increase in sensible heating in the same region $\left(+0.28 \mathrm{Wm}^{-2} \mathrm{a}^{-1}\right)$. This decrease in soil moisture translates to a 1990-2015 decrease in volumetric soil water content of $-2.2 \%$, within the range of what is observed as the JJAS difference between sunny and cloudy years at the Ameriflux $(-0.14 \%)$ and ICN (PER1 $=-3.0 \%$, PER2 $=-3.4 \%$ ) sites in Illinois. Since the precipitation patterns seem to be unchanging or small over much of the central US during 1990-2015, the LSM soil moisture results provide evidence of a climate response to greater evapotranspiration in the presence of enhanced SWdn.

We emphasize that our main goal in examining the 1990 2015 NLDAS dataset is to probe the regional response of soil moisture and temperature to trends in all-sky SWdn. Coincidentally, the trends in all-sky SWdn across the central US 

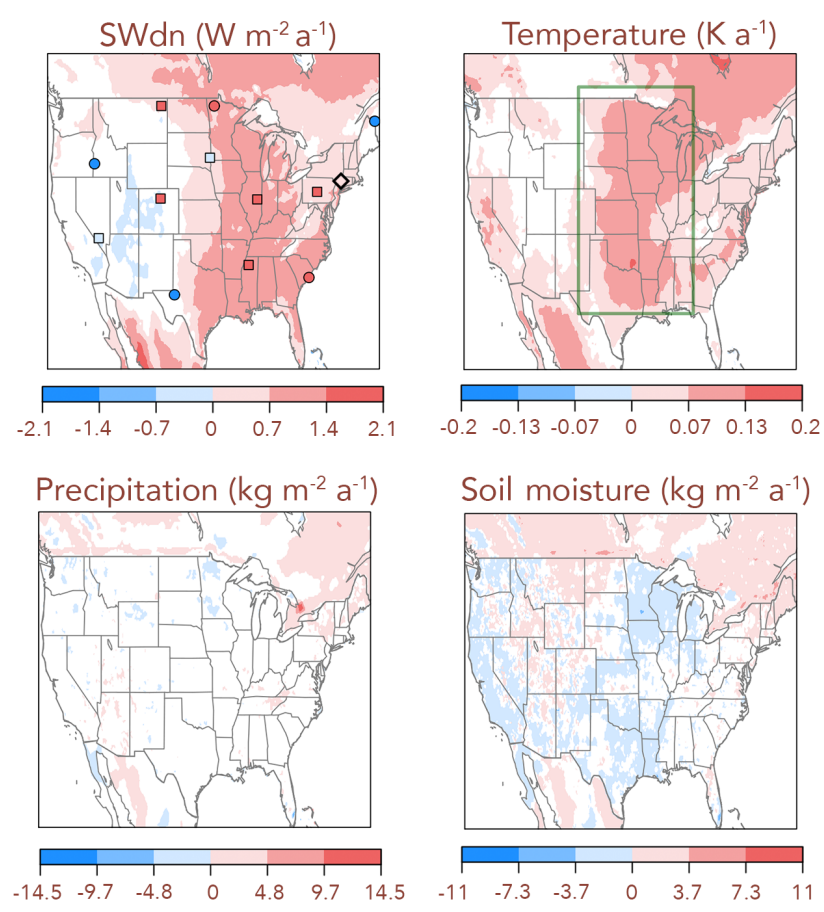

Figure 7. June-July-August-September (JJAS) trends in surface meteorological variables from 1990 to 2015. Surface downward solar radiation ( $\mathrm{SWdn}$ ), air temperature, and precipitation are assimilated from observations in the NASA Land Data Assimilation System (NLDAS). Overlaid on the SWdn plot are observed trends from the US Climate Reference Network (USCRN: circles, 20032014), SURFRAD (squares, 1997-2015), and the Cary Institute for Ecosystem Studies (CIES: diamond, 1990-2015). The green box in the temperature panel represents the central US $\left(30-50^{\circ} \mathrm{N}, 105-\right.$ $85^{\circ} \mathrm{W}$ ). In the soil moisture panel, we combine model results by first determining which of the LSM trends agree in sign in each grid cell and then showing the mean of just those models that agree. White indicates those regions that fail statistical significance (i.e., $p>0.05)$.

in the NLDAS dataset are similar in magnitude to the trends in clear-sky SWdn in the RRTMG_SW model at Bondville for a shorter time period. Given the similar magnitude of the observed all-sky and clear-sky SWdn trends and the covariability of AOD with clear-sky SWdn at Bondville, we infer the potential meteorological consequences of the observed AOD trends in the central US with greater confidence. This inference is limited due to the availability of just one surface site that measures direct and diffuse components of allsky SWdn, clear-sky SWdn, and AOD but can be used as an example of assessing aerosol-climate interactions in future studies.

\section{Discussion}

Here we assemble the evidence of changing surface climate in the US and consider the possible role of aerosols in driving this change. During the 2000-2014 time period, observed AOD decreases significantly at both Bondville, IL $(-0.047)$ and Goodwin Creek, MS (-0.052). Clear-sky total SWdn increases at these sites by $12.7 \mathrm{Wm}^{-2}$ (Bondville) and $7.8 \mathrm{Wm}^{-2}$ (Goodwin Creek) over the same time period, suggesting that the declining aerosols are at least partly responsible for these trends. All-sky total SWdn also increases at Goodwin Creek. However, the diffuse component of clear-sky SWdn increases at both Bondville $\left(+6.6 \mathrm{Wm}^{-2}\right)$ and Goodwin Creek $\left(+5.2 \mathrm{Wm}^{-2}\right)$, consistent with previous studies (e.g., Gan et al., 2014) and the cause of these increases remains an open question. We do not find evidence of aircraft contrails influencing observed diffuse SWdn at SURFRAD sites in the aftermath of 11 September 2001, and thus caution against attributing increasing clear-sky diffuse SWdn trends to increasing US air traffic as has been done in previous studies (e.g., Long et al., 2009; Augustine and Dutton, 2013).

Using the RRTMG_SW radiative transfer model driven by observed AOD, we simulate increases in total and direct clear-sky SWdn at both sites that are consistent with observations and decreases in diffuse SWdn that are contrary to the observations. Previous studies invoked trends in aircraft contrails to explain the unexpected changes in diffuse SWdn at SURFRAD sites across the US (e.g., Gan et al., 2014), but application of observed cirrus cloud fraction to RRTMG_SW does not resolve this issue. A cross-validated multivariate regression analysis further shows that observed monthly mean AOD accounts for $20 \%$ of the JJAS variability in clear-sky direct SWdn at Bondville, with cirrus cloud liquid water path and AOD reproducing $26 \%$ of the variability in clear-sky diffuse SWdn at this site. No combination of predictors, however, explains the variability of clear-sky direct or diffuse SWdn at Goodwin Creek, casting doubt on the role of aerosol-radiation interactions on local meteorology at this site. Besides AOD and cirrus cloud cover, we are left with few other variables that could influence the directdiffuse partitioning of clear-sky SWdn, and the cause of the observed increase in SWdn during the 2000-2014 time frame is not clear. With more sites across the southeast, we could diagnose these inconsistent results as either site-specific, or symptomatic of the larger region.

Our analysis of the Ameriflux data (1998-2007) and ICN data (1990-2014) suggests that soil moisture declines in response to enhanced solar radiation. In particular, we see possible evidence of a soil moisture feedback at the Bondville Ameriflux station, where the difference in JJAS SWdn between sunny and cloudy summers is nearly $30 \mathrm{Wm}^{-2}$, peaking in September. A sunny summer reduces soil moisture, especially in August (-3.5\%), and enhances sensible heat fluxes by $+8.7 \mathrm{Wm}^{-2}$, with peak values in September. The SURFRAD data show an all-sky annual SWdn trend of $+0.58 \mathrm{Wm}^{-2} \mathrm{a}^{-1}$ at Bondville and $\mathrm{a}+1.0 \mathrm{Wm}^{-2} \mathrm{a}^{-1}$ at Goodwin Creek for 2000-2014. This rate translates to changes in SWdn of +8.7 and $+15 \mathrm{Wm}^{-2}$ over this time 
period at these sites, or roughly one-fourth to one-half the change in SWdn between sunny and cloudy years at the Ameriflux station. Despite large spatial heterogeneity, the land surface models in Sect. 6 show a reduction of volumetric soil water content of as much as $-2.2 \%$ over the central US from 1990 to 2015. Given the observed trends in SWdn, this result is consistent in sign with the 0.14-3.4\% decrease in soil moisture content during sunnier summers at the Ameriflux and ICN sites in Illinois. The observed soil moisture and temperature responses between the sunny and cloudy regimes are of the same order of magnitude as those simulated by Mickley et al. (2012) for aerosol vs. no aerosol regimes over the eastern US, lending confidence to the conclusions of that model study. Our results are also consistent with Eshel (2016), who found that the observed SWdn increase from 1988 to 2014 at a rural site in the northeast could be explained in a radiative transfer model only when considering trends in anthropogenic aerosols.

Our Ameriflux, ICN, and NLDAS results show the climate response to increasing surface SWdn. The RRTMG_SW results in Bondville show that changing aerosols influences SWdn trends. Taken together, the observations and modeled results suggest that aerosol-radiation interactions are significant at Bondville, a conclusion doubted in previous studies (Long et al., 2009; Augustine and Dutton, 2013). We find evidence that these interactions play a role in the observed climate trends at Bondville, similar in response to modelling studies that probed the influence of aerosols on the warming hole (Leibensperger et al., 2012b). Changes in overhead aerosol contribute about one-fourth of the interannual variability in direct and diffuse clear-sky SWdn. If the aerosol trends at Bondville are representative of the larger region, the recent decline in AOD may partly account for the $1.8 \mathrm{~K}$ increase in surface temperatures across the larger region for JJAS in the NLDAS dataset. In contrast, aerosol-radiation interactions do not appear to contribute to the interannual variability in SWdn at Goodwin Creek, casting doubt on the role of the direct aerosol effect in the reversal of the US warming hole in the southeast.

Our results underscore the difficulty in attributing the warming hole to only aerosols or only aerosol-radiation interactions using observations. Even though we find evidence of aerosol-radiation interactions at Bondville, our result at Goodwin Creek contrasts with Tosca et al. (2017), who concluded that the observed increase in surface SWdn between 2007 and 2017 at this site was a result of aerosolradiation interactions. Though we agree with these authors on the sign of the observed surface SWdn trend and find that RRTMG_SW can indeed reproduce a positive clear-sky SWdn trend when driven by aerosols (Fig. 2), we do not find evidence of interannual covariability between AOD and clear-sky SWdn at Goodwin Creek. Hence, we disagree that the SURFRAD observations point to aerosol-radiation interactions at this site, as we believe that evidence of covariability between AOD and SWdn on interannual timescales is a necessary condition in asserting aerosol-radiation interactions. Yu et al. (2014), however, found evidence of aerosolcloud interactions in the southeastern US, so such interactions could potentially be important in that region.

Agriculture is a major industry in the central US, and decreases in soil moisture from increased SWdn may have made the region more vulnerable to drought, as suggested by previous model studies (Mickley et al., 2012; Leibensperger et al., 2012b). From our analysis of tower fluxes and the NLDAS assimilation, we find a consistent land-atmosphere response to SWdn as seen in these model studies. Specifically, soil moisture responds to local enhancements in SWdn that further amplifies SWdn, especially in late summer. Previous studies have diagnosed the strong influence of tropical Pacific SSTs on drought occurrence in the US (e.g., Schubert et al., 2004; Seager and Hoerling, 2014). However, drought models that rely on Pacific SSTs predict a prolonged drought during the 1970s, a period in reality characterized by increased precipitation, especially in the central and eastern United States (e.g., Seager and Hoerling, 2014). We speculate that high loading of anthropogenic aerosol during the 1970s may have led to more moist conditions in the central US, countering the SST influence and reducing drought risk. While the model results of Leibensperger et al. (2012a, b) are consistent with this hypothesis, more rigorous model studies with state-of-the-science hydrology and chemistry are needed to confirm it. We underscore the findings of other studies (e.g., Milly and Dunne, 2011) that caution modeling studies against projecting hydrological change in models without finding consistency with surface energy balance changes.

A drawback of this study is that it relies on relatively shortterm records of aerosols and surface SWdn. There is also some uncertainty in the SURFRAD measurements, at least when compared to the derived trends per year of SWdn. In trends reported here, however, we find that the standard deviation of the residual noise is greater than the instrument uncertainty. Finally, our study relies on just a few measurement sites to infer relationships of AOD with other variables across a broad region. We find evidence of aerosol-radiation interactions at Bondville but not Goodwin Creek. Though we use site-specific data to come to these conclusions, the good match between site measurements and assimilated NLDAS SWdn data, however, lends confidence that increased surface SWdn has indeed occurred over a broad region. As more in situ measurements of SWdn and AOD are recorded and as USCRN and other national networks are expanded, we expect the discrepancies between SURFRAD sites will be better explained.

This study provides observational evidence of the influence of AOD on SWdn and key variables such as soil moisture. By linking trends in AOD, SWdn, and soil moisture, our results point to the importance of considering atmospheric composition as an additional driver of drought. Currently, many regions of the developing world (e.g., China and In- 
dia) have much higher aerosol loading than the US and are planning strategies to reduce aerosol sources and improve air quality (Lu et al., 2011). These regions also depend on favorable meteorological conditions for agricultural production to feed growing populations. Our study suggests there may be inadvertent consequences of aerosol reduction on regional climate.

Data availability. The SURFRAD radiance and AOD observations are available for download at ftp://aftp.cmdl.noaa.gov/data/ radiation/surfrad/. ICN soil and meteorological data are available for download at http://www.isws.illinois.edu/warm/datatype. asp. Ameriflux soil and meteorological data are available for download at http://ameriflux.lbl.gov/. USCRN meteorological data are available for download at https://www.ncdc.noaa.gov/crn/ qcdatasets.html. CIES radiance data are available for download at https://cary-environmental-monitoring.squarespace.com/ metsolardata/. AERONET aerosol inversion products are available for download at https://aeronet.gsfc.nasa.gov/. CERES Level 3 cloud data products are available for download at https://ceres. larc.nasa.gov/order_data.php. MERRA-2 and NLDAS reanalyses are available for download at https://disc.gsfc.nasa.gov/. Instructions and model code for the radiative transfer model RRTMG_SW is available for download at http://rtweb.aer.com/rrtm_frame.html.

\section{The Supplement related to this article is available online at https://doi.org/10.5194/acp-17-13559-2017- supplement.}

Competing interests. The authors declare that they have no conflict of interest.

Acknowledgements. This work was supported by the National Aeronautics and Space Administration, MAP grant NNX13AO08G.

Edited by: Yun Qian

Reviewed by: three anonymous referees

\section{References}

Augustine, J. A. and Dutton, E. G.: Variability of the surface radiation budget over the United States from 1996 through 2011 from high-quality measurements, J. Geophys. Res.-Atmos., 118, 43-53, 2013.

Augustine, J. A., DeLuisi, J. J., and Long, C. N.: SURFRAD-A national surface radiation budget network for atmospheric research, B. Am. Meteorol. Soc., 81, 2341-2357, 2000.

Banerjee, A., Polvani, L., and Fyfe, J.: The United States "warming hole": Quantifying the forced aerosol response given large internal variability, Geophys. Res. Lett., 44, 1928-1937, 2017.

Bond, T. C., Bhardwaj, E., Dong, R., Jogani, R., Jung, S., Roden, C., Streets, D. G., and Trautmann, N. M.: Historical emissions of black and organic carbon aerosol from energyrelated combustion, 1850-2000, Global Biogeochem. Cy., 21, https://doi.org/10.1029/2006GB002840, 2007.

Bond, T. C., Doherty, S. J., Fahey, D., Forster, P., Berntsen, T., DeAngelo, B., Flanner, M., Ghan, S., Kärcher, B., Koch, D., Kinne, S., Kondo, Y., Quinn, P. K., Sarofim, M. C., Schultz, M. G., Schulz, M., Venkataraman, C., Zhang, H., Zhang, S., Bellouin, N., Guttikunda, S. K., Hopke, P. K., Jacobson, M. Z., Kaiser, J. W., Klimont, Z., Lohmann, U., Schwarz, J. P., Shindell, D., Storelvmo, T., Warren, S. G., and Zender, C. S.: Bounding the role of black carbon in the climate system: A scientific assessment, J. Geophys. Res.-Atmos., 118, 5380-5552, 2013.

Booth, B. B., Dunstone, N. J., Halloran, P. R., Andrews, T., and Bellouin, N.: Aerosols implicated as a prime driver of twentiethcentury North Atlantic climate variability, Nature, 484, 228-232, 2012.

Budyko, M. I.: The effect of solar radiation variations on the climate of the earth, Tellus, 21, 611-619, 1969.

Clough, S., Shephard, M., Mlawer, E., Delamere, J., Iacono, M., Cady-Pereira, K., Boukabara, S., and Brown, P.: Atmospheric radiative transfer modeling: a summary of the AER codes, J. Quant. Spectrosc. Ra., 91, 233-244, 2005.

Diamond, H. J., Karl, T. R., Palecki, M. A., Baker, C. B., Bell, J. E., Leeper, R. D., Easterling, D. R., Lawrimore, J. H., Meyers, T. P., Helfert, M. R., Goodge G., and Thorne, P. W.: US Climate Reference Network after one decade of operations: Status and assessment, B. Am. Meteorol. Soc., 94, 485-498, 2013.

Dubovik, O. and King, M. D.: A flexible inversion algorithm for retrieval of aerosol optical properties from Sun and sky radiance measurements, J. Geophys. Res., 105, 20673-20696, 2000.

Eshel, G.: Recent Southern New York Climate Change: Observations, Mechanisms, and Spatial Context, J. Climate, 29, 209-226, 2016.

Gan, C.-M., Pleim, J., Mathur, R., Hogrefe, C., Long, C. N., Xing, J., Roselle, S., and Wei, C.: Assessment of the effect of air pollution controls on trends in shortwave radiation over the United States from 1995 through 2010 from multiple observation networks, Atmos. Chem. Phys., 14, 1701-1715, https://doi.org/10.5194/acp-14-1701-2014, 2014.

Gu, L., Meyers, T., Pallardy, S. G., Hanson, P. J., Yang, B., Heuer, M., Hosman, K. P., Riggs, J. S., Sluss, D., and Wullschleger, S. D.: Direct and indirect effects of atmospheric conditions and soil moisture on surface energy partitioning revealed by a prolonged drought at a temperate forest site, J. Geophys. Res.-Atmos., 111, https://doi.org/10.1029/2006JD007161, 2006.

Hong, G., Yang, P., Minnis, P., Hu, Y. X., and North, G.: Do contrails significantly reduce daily temperature range?, Geophys. Res. Lett., 35, https://doi.org/10.1029/2008GL036108, 2008.

Iacono, M. J., Delamere, J. S., Mlawer, E. J., Shephard, M. W., Clough, S. A., and Collins, W. D.: Radiative forcing by long-lived greenhouse gases: Calculations with the AER radiative transfer models, J. Geophys. Res.-Atmos., 113, https://doi.org/10.1029/2008JD009944, 2008.

Koch, D. and Del Genio, A. D.: Black carbon semi-direct effects on cloud cover: review and synthesis, Atmos. Chem. Phys., 10, 7685-7696, https://doi.org/10.5194/acp-10-7685-2010, 2010.

Koster, R. D. and Suarez, M. J.: The components of a SVAT scheme and their effects on a GCM's hydrological cycle, Adv. Water Resour., 17, 61-78, 1994. 
Kumar, S., Kinter III, J., Dirmeyer, P. A., Pan, Z., and Adams, J.: Multidecadal Climate Variability and the Warming Hole in North America: Results from CMIP5 Twentieth-and TwentyFirst-Century Climate Simulations, J. Climate, 26, 3511-3527, 2013.

Leibensperger, E. M., Mickley, L. J., Jacob, D. J., Chen, W.T., Seinfeld, J. H., Nenes, A., Adams, P. J., Streets, D. G., Kumar, N., and Rind, D.: Climatic effects of 1950-2050 changes in US anthropogenic aerosols - Part 1: Aerosol trends and radiative forcing, Atmos. Chem. Phys., 12, 3333-3348, https://doi.org/10.5194/acp-12-3333-2012, 2012a

Leibensperger, E. M., Mickley, L. J., Jacob, D. J., Chen, W.-T., Seinfeld, J. H., Nenes, A., Adams, P. J., Streets, D. G., Kumar, N., and Rind, D.: Climatic effects of 1950-2050 changes in US anthropogenic aerosols - Part 2: Climate response, Atmos. Chem. Phys., 12, 3349-3362, https://doi.org/10.5194/acp12-3349-2012, 2012b.

Long, C. N. and Ackerman, T. P.: Identification of clear skies from broadband pyranometer measurements and calculation of downwelling shortwave cloud effects, J. Geophys. Res.-Atmos., 105, 15609-15626, 2000.

Long, C. N., Dutton, E. G., Augustine, J., Wiscombe, W., Wild, M., McFarlane, S. A., and Flynn, C. J.: Significant decadal brightening of downwelling shortwave in the continental United States, J. Geophys. Res.-Atmos., 114, https://doi.org/10.1029/2008JD011263, 2009.

Lu, Z., Zhang, Q., and Streets, D. G.: Sulfur dioxide and primary carbonaceous aerosol emissions in China and India, 1996-2010, Atmos. Chem. Phys., 11, 9839-9864, https://doi.org/10.5194/acp-11-9839-2011, 2011.

Malm, W. C., Schichtel, B. A., Pitchford, M. L., Ashbaugh, L. L., and Eldred, R. A.: Spatial and monthly trends in speciated fine particle concentration in the United States, J. Geophys. Res.Atmos., 109, https://doi.org/10.1029/2003JD003739, 2004.

Mascioli, N. R., Fiore, A. M., Previdi, M., and Correa, G.: Temperature and Precipitation Extremes in the United States: Quantifying the Responses to Anthropogenic Aerosols and Greenhouse Gases, J. Climate, 29, 2689-2701, 2016.

Meehl, G. A., Arblaster, J. M., and Branstator, G.: Mechanisms contributing to the warming hole and the consequent US east-west differential of heat extremes, J. Climate, 25, 6394-6408, 2012.

Melillo, J. M., Richmond, T. T., and Yohe, G.: Climate change impacts in the United States, Third National Climate Assessment, 2014.

Mickley, L., Leibensperger, E., Jacob, D., and Rind, D.: Regional warming from aerosol removal over the United States: Results from a transient 2010-2050 climate simulation, Atmos. Environ., 46, 545-553, 2012.

Milly, P. C. and Dunne, K. A.: On the hydrologic adjustment of climate-model projections: The potential pitfall of potential evapotranspiration, Earth Interact., 15, 1-14, 2011.

Minnis, P., Nguyen, L., Duda, D. P., and Palikonda, R.: Spreading of isolated contrails during the 2001 air traffic shutdown, in: 10th Conference on Aviation, Range and Aerospace Meteorology, 2002.

Minnis, P., Ayers, J. K., Palikonda, R., and Phan, D.: Contrails, cirrus trends, and climate, J. Climate, 17, 1671-1685, 2004.

Minnis, P., Sun-Mack, S., Young, D. F., Heck, P. W., Garber, D.P., Chen, Y., Spangenberg, D. A., Arduini, R. F., Trepte, Q. Z.,
Smith, W. L., Ayers, K., Gibson, S. C., Miller, W. F., Hong, G., Chakrapani, V., Takano, Y., Liou, K. N., Xie, Y., and Yang, P.: CERES edition-2 cloud property retrievals using TRMM VIRS and Terra and Aqua MODIS data, Part I: Algorithms, IEEE T. Geosci. Remote, 49, 4374-4400, 2011.

Mitchell, K. E., Lohmann, D., Houser, P. R., Wood, E. F., Schaake, J. C., Robock, A., Cosgrove, B. A., Sheffield, J., Duan, Q., Luo, L., Higgins, R. W., Pinker, R. T., Tarpley, J. D., Lettenmaier, D. P., Marhsall, C. H., Entin, J. K., Pan, M., Shi, S., Koren, V., Meng, J., Ramsay, B. H., and Bailey, A. A.: The multiinstitution North American Land Data Assimilation System (NLDAS): Utilizing multiple GCIP products and partners in a continental distributed hydrological modeling system, J. Geophys. Res.-Atmos., 109, https://doi.org/10.1029/2003JD003823, 2004.

Mueller, N. D., Butler, E. E., McKinnon, K. A., Rhines, A., Tingley, M., Holbrook, N. M., and Huybers, P.: Cooling of US Midwest summer temperature extremes from cropland intensification, $\mathrm{Na}-$ ture Climate Change, 6, 317-22, 2016.

Overgaard, J. and Rosbjerg, D.: Energy-based land-surface modelling: new opportunities in integrated hydrological modelling, Technical University of DenmarkDanmarks Tekniske Universitet, Department of Hydrodynamics and Water ResocurcesStrømningsmekanik og Vandressourcer, 2011.

Pan, Z., Arritt, R. W., Takle, E. S., Gutowski, W. J., Anderson, C. J., and Segal, M.: Altered hydrologic feedback in a warming climate introduces a warming hole, Geophys. Res. Lett., 31, https://doi.org/10.1029/2004GL020528, 2004.

Philipona, R., Behrens, K., and Ruckstuhl, C.: How declining aerosols and rising greenhouse gases forced rapid warming in Europe since the 1980s, Geophys. Res. Lett., 36, https://doi.org/10.1029/2008GL036350, 2009.

Pinker, R. T., Tarpley, J. D., Laszlo, I., Mitchell, K. E., Houser, P. R., Wood, E. F., Schaake, J. C., Robock, A., Lohmann, D., Cosgrove, B. A., Sheffield, J., Duan, Q., Luo, L., and Higgins, R. W. Surface radiation budgets in support of the GEWEX ContinentalScale International Project (GCIP) and the GEWEX Americas Prediction Project (GAPP), including the North American Land Data Assimilation System (NLDAS) project, J. Geophys. Res.Atmos., 108, https://doi.org/10.1029/2002JD003301, 2003.

Posada, D. and Buckley, T. R.: Model selection and model averaging in phylogenetics: advantages of Akaike information criterion and Bayesian approaches over likelihood ratio tests, Syst. Biol., 53, 793-808, 2004.

Rienecker, M. M., Suarez, M. J., Gelaro, R., Todling, R., Bacmeister, J., Liu, E., Bosilovich, M. G., Schubert, S. D., Takacs, L., Kim, G. K., Bloom, S., Chen, J., Collins, D., Conaty, A., da Silva, A., Gu, W., Joiner, J., Koster, R. D., Lucchesi, R., Molod, A., Owens, T., Pawson, S., Pegion, P., Redder, C. R., Reichle, R., Robertson, F. R., Ruddick, A. G., Sienkiewicz, M., and Woollen, J.: MERRA: NASA's modern-era retrospective analysis for research and applications, J. Climate, 24, 3624-3648, 2011.

Ruckstuhl, C., Philipona, R., Behrens, K., Collaud Coen, M., Dürr, B., Heimo, A., Mätzler, C., Nyeki, S., Ohmura, A., Vuilleumier, L., Weller, M., Wehrli, C., and Zelenka, A.: Aerosol and cloud effects on solar brightening and the recent rapid warming, Geophys. Res. Lett., 35, https://doi.org/10.1029/2008GL034228, 2008.

Ruiz-Arias, J. A., Dudhia, J., Santos-Alamillos, F. J., and PozoVázquez, D.: Surface clear-sky shortwave radiative closure in- 
tercomparisons in the Weather Research and Forecasting model, J. Geophys. Res.-Atmos., 118, 9901-9913, 2013.

Ruiz-Arias, J. A., Gueymard, C. A., Santos-Alamillos, F. J., Quesada-Ruiz, S., and Pozo-Vázquez, D.: Bias induced by the AOD representation time scale in long-term solar radiation calculations. Part 2: Impact on long-term solar irradiance predictions, Sol. Energy, 135, 625-632, 2016.

Schubert, S. D., Suarez, M. J., Pegion, P. J., Koster, R. D., and Bacmeister, J. T.: On the cause of the 1930s Dust Bowl, Science, 303, 1855-1859, 2004.

Seager, R. and Hoerling, M.: Atmosphere and Ocean Origins of North American Droughts, J. Climate, 27, 4581-4606, 2014.

Shindell, D. T., Schmidt, G. A., Miller, R. L., and Mann, M. E.: Volcanic and solar forcing of climate change during the preindustrial era, J. Climate, 16, 4094-4107, 2003.

Soden, B. J. and Held, I. M.: An assessment of climate feedbacks in coupled ocean-atmosphere models, J. Climate, 19, 3354-3360, 2006.

Stoffel, T.: Solar infrared radiation station (SIRS) handbook, Atmospheric Radiation Measurement Program Technical Report ARM TR-025, 2005.

Suarez, M. J., Rienecker, M., Todling, R., Bacmeister, J., Takacs, L., Liu, H., Gu, W., Sienkiewicz, M., Koster, R., Gelaro, R., Stajner I., and Nielsen J. E.: The GEOS-5 Data Assimilation SystemDocumentation of Versions 5.0.1, 5.1.0, and 5.2.0, 2008.

Tosca, M. G., Campbell, J., Garay, M., Lolli, S., Seidel, F. C., Marquis, J., and Kalashnikova, O.: Attributing Accelerated Summertime Warming in the Southeast United States to Recent Reductions in Aerosol Burden: Indications from Vertically-Resolved Observations, Remote Sensing, 9, 674, 2017.

Travis, D. J., Carleton, A. M., and Lauritsen, R. G.: Regional variations in US diurnal temperature range for the 11-14 September 2001 aircraft groundings: evidence of jet contrail influence on climate, J. Climate, 17, 1123-1134, 2004.

USEPA: Our Nation's Air: Status and Trends Through 2010, 2012. WARM: Water and atmospheric resources monitoring program, 2005.
WARM: Water and Atmospheric Resources Monitoring Program, Illinois Climate Network, Illinois State Water Survey, 2204 Griffith Drive, Champaign, IL 61820-7495, 2014.

Weatherhead, E. C., Reinsel, G. C., Tiao, G. C., Meng, X.-L., Choi, D., Cheang, W.-K., Keller, T., DeLuisi, J., Wuebbles, D. J., Kerr, J. B., Miller, A. J., Oltmans, S. J., and Frederick, J. E.: Factors affecting the detection of trends: Statistical considerations and applications to environmental data, J. Geophys. Res., 103, 17149, 1998.

Westervelt, D. M., Horowitz, L. W., Naik, V., Golaz, J.-C., and Mauzerall, D. L.: Radiative forcing and climate response to projected 21 st century aerosol decreases, Atmos. Chem. Phys., 15, 12681-12703, https://doi.org/10.5194/acp-15-12681-2015, 2015.

Wood, E. F., Lettenmaier, D., Liang, X., Nijssen, B., and Wetzel, S. W.: Hydrological modeling of continental-scale basins, Annu. Rev. Earth Planet. Sc., 25, 279-300, 1997.

Xia, Y., Mitchell, K., Ek, M., Sheffield, J., Cosgrove, B., Wood, E., Luo, L., Alonge, C., Wei, H., Meng, J., Livneh, B., Lettenmaier, D., Koren, V., Duan, W., Mo, K., Fan, Y., and Mocko, D.: Continental-scale water and energy flux analysis and validation for the North American Land Data Assimilation System project phase 2 (NLDAS-2): 1. Intercomparison and application of model products, J. Geophys. Res.-Atmos., 117, https://doi.org/10.1029/2011JD016048, 2012.

Yu, S., Alapaty, K., Mathur, R., Pleim, J., Zhang, Y., Nolte, C., Eder, B., Foley, K., and Nagashima, T.: Attribution of the United States warming hole: Aerosol indirect effect and precipitable water vapor, Scientific reports, 4, 6929, https://doi.org/10.1038/srep06929, 2014.

Zhang, R., Delworth, T. L., Sutton, R., Hodson, D. L., Dixon, K. W., Held, I. M., Kushnir, Y., Marshall, J., Ming, Y., Msadek, R., Robson, J., Rosati, A. J., Ting, M., and Vecchi, G. A.: Have aerosols caused the observed Atlantic multidecadal variability?, J. Atmos. Sci., 70, 1135-1144, 2013. 